\title{
REMOÇÕES E REAÇÕES: AÇÕES DE EXCEÇÃO E PRÁTICAS DO COMUM NA PERIFERIA DE BRASÍLIA
}

\author{
Laila Beatriz da Rocha Loddi ${ }^{1}$ \\ Carlos Henrique Magalhães de Lima²
}

DOI: $10.5752 / P .2316-1752.2019 v 26 n 39 p 294$

\section{Resumo}

Neste artigo abordam-se modos de produção do espaço conduzidos por organizações populares em duas localidades de Brasília atravessadas pela prática urbanística das remoções. Uma análise longitudinal investigará a erradicação de invasões que resultou em Ceilândia. Já na análise de conjuntura, investiga-se a constante possibilidade de remoção enfrentada por moradores da Cidade Estrutural. Teoricamente, mobiliza-se parte da literatura recente a respeito do comum para propor uma reflexão sobre essa produção de espaço, apontando possíveis enfrentamentos das desigualdades socioespaciais no presente.

\footnotetext{
1. Arquiteta e Urbanista pela UFSC, mestre em Arte e Cultura Visual pela UFG, doutoranda do Programa de Pós-Graduação em Arquitetura e Urbanismo da Universidade de Brasília. Professora da Universidade Estadual de Goiás. E-mail: laila.loddi@ueg.br.

2. Arquiteto e Urbanista pela Universidade de Brasília-UnB, Doutor em Urbanismo pela Universidade Federal do Rio de Janeiro. Professor da Universidade de Brasília. E-mail: carloshenrique@ unb.br.
} 
Palavras-chave: Remoções. Resistências. Comum. Produção do espaço. Brasília. 
REMOVALS AND REACTIONS: URBANISM OF EXCEPTION AND COMMON PRACTICES ON THE PERIPHERY OF BRASÍLIA

\begin{abstract}
This article discusses ways of producing space conducted by popular organizations in two locations in Brasilia, crossed by the urbanistic practice of removals. A longitudinal analysis will investigate the invasion eradication that resulted in Ceilâandia. In the conjuncture analysis, the constant possibility of removal faced by residents of Cidade Estrutural is investigated. Theoretically, is mobilize part of the recent literature about the commons to propose a reflection on this production of space, pointing out possible confrontations of socio-spatial inequalities in the present.
\end{abstract}

Keywords: Removals. Resistances. Commons. Space production. Brasília.
REMOCIONES $Y$ REACCIONES: URBANISMO DE EXCEPCIÓN Y PRÁCTICAS DE PRÓCOMUN EN LA PERIFERIA DE BRASILIA

\section{Resumen}

Este artículo discute formas de producir espacio conducido por organizaciones populares en dos lugares en Brasília, atravesados por la práctica urbanística de las remociones. Un análisis longitudinal investigará la erradicación de la invasión que resultó en Ceilândia. En el análisis de la coyuntura, se investiga la posibilidad constante de remoción que enfrentan los residentes de Cidade Estrutural. Teóricamente, movilizarse parte de la literatura reciente sobre lo prócomún para proponer una reflexión sobre esta producción de espacio, señalando posibles confrontaciones de desigualdades socio-espaciales en el presente.

Palabras-claves: Remociones. Resistencias.

Prócomun. Producción espacial. Brasilia. 


\section{Introdução}

Este trabalho surge pelo interesse em práticas culturais, artísticas e espaciais contra hegemonias elaboradas nas periferias das cidades - denominadas aqui reações. Populações minoritárias reagem diante de situações de violência ou indeterminação, muitas das quais produzidas na perspectiva de um urbanismo supressivo que pouco ou nada considera demandas e experiências de populações locais. Em "8 reações para o depois" (2019), a noção de reação aparece na análise de casos de violação de direitos humanos no Rio de Janeiro - movimentado pelos megaeventos de 2014 e 2016 -, nos quais as reações "surgem como forças que, em disputa, afetam e desestabilizam o território, derivadas de ocorrências antigas e insurgentes" (ALTBERG; MENEGUETTI; KOSLOWSKI [Coord.] 2019, p.2). Dentre as violações urbanísticas, identificam-se operações sobre populações pobres, de remoção, desestabilização de lugares, apagamento de memórias, agressões e outros conflitos realizados pelo Estado associado a empresas e instituições. A existência destas comunidades parece dificultar as metas do almejado projeto de cidade que pouco assimila das experiências de vida identificadas em uma base social heterogênea e complexa.

Pensamento e prática do urbanismo influenciam decisivamente no agenciamento dos lugares, na distribuição das populações, nos fluxos de pessoas e de capitais, quase 
sempre em sintonia com os campos caracterizados pela teoria política como hegemônicos. As situações apresentadas aqui configuram práticas urbanísticas e nos levam a extrair consequências teóricas e experimentais para sua crítica. Tais casos revelam ações de exceção, mas também nos permitem levantar reações produzidas por aqueles que são negativamente afetados pelos processos. Assimilando a ideia de que tal tensão não se resume ao confronto entre subordinação e controle, propõe-se uma leitura que parte do polo minoritário em direção ao vértice determinante. Foi elaborada uma abordagem teórico-empírica na tentativa de compreender fenômenos que atravessam duas situações separadas por certo lapso temporal, ambas em Brasília. Em 1970, o governo local conduziu a chamada Campanha de Erradicação de Invasões, cujo intuito era evitar a incrustação de favelas no entorno imediato do Plano Piloto da cidade. Hoje, vive-se na Cidade Estrutural a constante insegurança jurídico-urbanística que tem no horizonte a possibilidade de remoção.

Por um lado, a prática urbanística será aqui associada aos dispositivos, mecanismos de controle. O mecanismo é uma meada, um conjunto multilinear 
aproximam ora se afastam uma das outras (DELEUZE, 1996, p.65).

Por outro lado, procura-se uma abertura às potencialidades constituídas nas urdiduras das formas de resistências articuladas nesses territórios pela população local, apostando que as linhas de fuga podem levar à construção de um comum assentado em práticas e discursos de coletivos autodefinidos. Territórios esses como os "territórios para a vida" que Raquel Rolnik (2019) observa: organizados a partir da lógica da sobrevivência, das necessidades e dos desejos:

\begin{abstract}
Planejamento conflitual, planejamento abolicionista e planejamento insurgente têm sido denominações utilizadas hoje na teoria do planejamento para designar práticas contra-hegemônicas que, beneficiando-se da natureza contraditória do capitalismo neoliberal, contribuem para liberar as forças de transgressão e imaginação presentes nos territórios para a vida, sejam esses os assentamentos autoconstruídos, as ocupações efêmeras ou de longa duração. São práticas fluidas, que se movem através dos espaços institucionais de participação, mas que também adotam formas de organização/ decisão definidas, em seus próprios termos, por seus participantes e protagonistas (ROLNIK, 2019, p.39).
\end{abstract}

Em suma, objetiva-se contrapor situações e reações para produzir uma leitura a respeito do urbanismo como dispositivo de controle, procurando observar autoexpressões espaciais que podem oferecer compreensões alternati- 
vas da sociedade, em direção aos esforços que se somam em favor de cidades mais justas e viáveis.

\section{Remoção: prática urbanística e dispositivo dis- ciplinar - o caso de Ceilândia}

A história de Ceilândia é bastante conhecida por historiadores da cidade e do urbanismo. Até o final da década de 1960, muitos dos trabalhadores que migraram para a construção de Brasília já haviam sido removidos dos acampamentos operários de caráter provisório no Plano Piloto. A fixação de famílias de migrantes no entorno do Plano Piloto cresceu na mesma medida em que o Plano se firmava como centro de empregos e serviços. Já nesse período, "consolidou-se uma política de remoção de favelas ou ocupações irregulares para o assentamento de populações mais pobres em subúrbios-dormitório, as chamadas cidades-satélites" (DERNTL, 2018). Taguatinga (1958), Sobradinho (1959), Cidade Livre (Núcleo Bandeirante, 1961), Guará (1967) foram criadas para receber essas famílias. Ainda assim, os assentamentos próximos ao Plano Piloto se multiplicavam.

O complexo da Vila IAPI (próximo ao Hospital do Instituto de Aposentadorias e Pensões dos Industriários), na região da Cidade Livre, posteriormente denominado Núcleo Bandeirante, era um dos mais populosos. Segundo divulgado pela imprensa da época, o então presidente Mé- 
dici teria manifestado desagrado com as 'numerosas e incomodativas invasões' em seu trajeto para o Palácio do Planalto e deste para o sítio em Riacho Fundo (PAVIANI, 1991). Antes dele, o próprio Lucio Costa já havia advertido sobre a necessidade de um modelo de ocupação do território que impedisse a "enquistação de favelas, tanto na periferia urbana quanto na rural" (COSTA, 2007 [1962]). Atendendo à queixa presidencial e tentando coibir a proliferação de favelas prevista por Costa, o governador do Distrito Federal, coronel Hélio Prates da Silveira, lança em 1970 a Campanha de Erradicação de Invasões (CEI). Aldo Paviani relata as condições em que foram realizadas as transferências:

[A CEI] entre os anos de 1971 e 1972 cadastrou todos os barracos existentes nas vilas periféricas ao Núcleo Bandeirante, transferindo posteriormente sua população para a nova localidade de Ceilândia. Em razão do aparato montado, a transferência se deu sem que os percalços (poeira, lama, falta de água e trabalho) constituíssem motivo de revolta dos transferidos. O 'comportamento adequado' dos favelados foi também atribuído à promessa de legalização dos terrenos a baixo custo e pronta instalação de equipamentos como escolas, água encanada e eletricidade, facilidades que não eram encontradas nos acampamentos e favelas da periferia do Núcleo Bandeirante. (PAVIANI, 1991, p.129).

Moradores da Vila IAPI, Morro do Urubu, Morro do Querosene, assentamentos de Bernardo Saião, Curral das Éguas e Placas das Mercês foram removidos para um lo- 
cal mais distante e sem qualquer infraestrutura. À época, um relatório do governo reconhecia qualidades urbanísticas e comunitárias da Vila IAPI, mas, ainda assim, justificava sua remoção baseado em laudos que atribuíam à ocupação a contaminação de córregos próximos (GOUVÊA, 1995, p. 67).

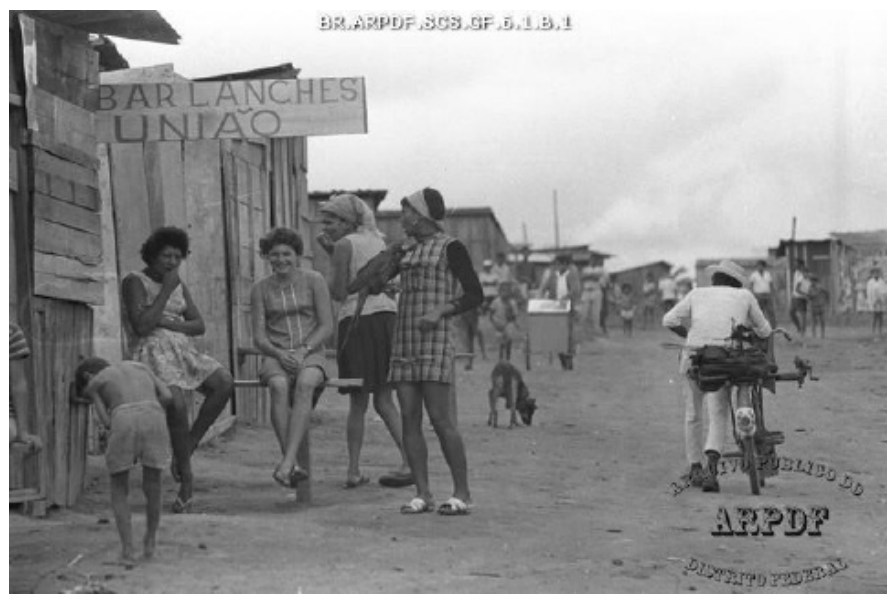

Figura 1 | Vila IAPI, Núcleo Bandeirante, 1969

Fonte: Arquivo Público do Distrito Federal

Identifica-se nessa situação parte de um fenômeno urbano experimentado e fundado na construção de Brasília, que vem sendo amplamente pesquisado em diferentes campos pelo viés da concepção e urbanização da cidade. No entanto, intentou-se compreender a Campanha de Erradicação de Invasões como "dispositivo disciplinar" ca- 
muflado sob discurso civilizatório, modernizador e desenvolvimentista. O aparato discursivo empregado ao longo da CEI revela um processo de cunho colonialista fortemente marcado pelo domínio e controle das formas de espacialização de populações subalternizadas. O termo "dispositivo" aparece com ênfase nos textos de Foucault (2000) e Agamben (2005). O primeiro emprega do termo para demarcar sobretudo "um conjunto decididamente heterogêneo que engloba discursos, instituições, organizações arquitetônicas, decisões regulamentares, leis, medidas administrativas, enunciados científicos, proposições filosóficas, morais, filantrópicas." (FOUCAULT, 2000, p. 244). Em síntese, dispositivo é a rede que se pode estabelecer entre esses elementos, estejam enunciados ou não. Agamben, por sua vez, propõe um deslocamento semântico do conceito, em um quadro contemporâneo de acirramento das questões refletidas por Foucault. Segundo Agamben (2005, p.13), dispositivo é

[...] qualquer coisa que tenha de algum modo a capacidade de capturar, orientar, determinar, interceptar, modelar, controlar e assegurar os gestos, as condutas, as opiniões e os discursos dos seres viventes. Não somente, portanto, as prisões, os manicômios, o panóptico, as escolas, as confissões, as fábricas, as disciplinas, as medidas jurídicas etc., cuja conexão com o poder e em um certo sentido evidente, mas também a caneta, a escritura, a literatura, a filosofia, a agricultura, o cigarro, a navegação, os computadores, os telefones celulares e - porque não - a linguagem mesma, que é talvez o 
mais antigo dos dispositivos, em que há milhares e miIhares de anos um primata - provavelmente sem dar-se conta das consequências que se seguiriam - teve a inconsciência de se deixar capturar.

Por meio "de uma série de práticas e de discursos, de saberes e de exercícios, [os dispositivos visam] a criação de corpos dóceis, mas livres, que assumem a sua identidade e a sua "liberdade" enquanto sujeitos no processo mesmo do seu assujeitamento." (AGAMBEN, 2005, p.14, ênfase nossa).

O aspecto da linguagem é ressaltado por Spivak (2010) em sua reflexão sobre a condição subalterna no capitalismo global. Se a própria linguagem é um dispositivo, com que voz/consciência poderia o próprio sujeito subalterno falar? Sujeito esse pertencente "às camadas mais baixas da sociedade constituídas pelos modos específicos de exclusão dos mercados, da representação política e legal, e da possibilidade de se tornarem membros plenos no estrato social dominante" (SPIVAK, 2010, p.12). Isto é, na formação programada da desigualdade operada por violência epistêmica impõe-se o poder de falar em nome do subalterno - prática recorrente em diversas fases da história do colonialismo - cuja fala estaria capturada nas estruturas do poder hegemônico. A abordagem de Spivak contribui para aguçar questionamentos sobre a CEI enquanto estratégia colonizadora e ideológica afirmada por meio da linguagem. 
Em se tratando de locais de residência/permanência/ existência de populações pobres, está em disputa uma questão de linguagem: a narrativa da precariedade se sobrepõe às alternativas criadas pela população para resolver sua necessidade de morar, criando tipificações e legalismos que tratam sempre como precário e anormal o que de fato poderia ser descrito como 'possível na cidade neoliberal'. A pobreza, assim, é relacionada apenas à falta e à deficiência, naturalizando e ocultando parte dos significados desse vocabulário recorrente. Assentamentos chamados "invasões", "precários", "inadequados", "subnormais", "ilegais" - entre outras nomenclaturas técnicas largamente utilizadas - evidenciam distanciamentos, preconceitos e estigmas, além de esconder estratégias de apropriação de territórios com finalidades especulativas. A habitação autoproduzida nas periferias e favelas pode ser compreendida como esforço da população de baixa renda em cidades injustas e desiguais. No jogo de linguagem da ilegalidade não há reconhecimento da legitimidade das práticas existentes, tampouco valorização da leitura a respeito do território elaborada pelos próprios moradores. O vocabulário da criminalização naturaliza situações de violência, como a remoção das chamadas invasões do Plano Piloto nos anos 1960.

Oliveira (2014) apresenta um trabalho etnográfico comparativo entre dois casos raramente aproximados: ações do Estado sobre populações indígenas e sobre favelas 
cariocas. O autor afirma que na gestão tutelar desses territórios há a construção de um "outro" por meio de categorias e processos de classificação social, normatização e imposição de práticas ${ }^{3}$. No caso das favelas, o termo pacificação confere às ações da polícia militar do RJ e das forças armadas as mesmas qualidades cívicas e de intenção humanitária atribuídas às atividades indigenistas do governo brasileiro no período dos heróis sertanistas como Marechal Rondon. Segundo Oliveira, isso se dá com intuito de pacificar, civilizar; trazer os selvagens, pagãos, imorais, à luz da civilidade; ainda que sejam outros os interesses de apropriação desses territórios. Quem há de contestar o discurso da pacificação, da erradicação de invasões ou do desenvolvimento?

$\mathrm{Na}$ condução de projetos em áreas ocupadas por populações de baixa renda, o Estado tem se associado ao capital privado, com objetivos especulativos e resultando em segregação socioespacial. Não se propõe solucionar o problema; apenas administrá-lo, contorná-lo, redefinindo os lugares da violência e da precariedade por um tipo de agenciamento urbano parcial e incompleto. As obras beneficiam pontos estratégicos do território: aqueles que apresentam relevância imediata. Esse modelo urbano é

3. Conforme observam Batista (2011), Brito (2013), Menegat (2013), Teixeira (2012), Barreira e Botelho (2013), a "pacificação urbana" em algumas favelas cariocas teve o intuito de contornar e administrar o crescimento da violência no Rio de Janeiro das últimas décadas, que ultrapassou as barreiras das favelas e tornou-se ameaça à coesão social e política da cidade. 
voltado a uma minoria de consumidores, para forjar uma imagem de cidade sem conflitos, atraente, desenvolvida e segura para investimentos (BARREIRA, 2013).

Para Escobar (2008), 'desenvolvimento' é uma ideologia atrelada ao poder e um conceito que vem sendo incorporado indiscutivelmente ao discurso técnico, justificando a implantação de megaprojetos e o investimento em grandes obras. O autor levanta críticas ao paradigma desenvolvimentista e aponta sua inadequação, propondo a urgência da fundação de novos paradigmas pautados pelo conhecimento local. A partir dessa redefinição, considera-se que modelos de desenvolvimento não conseguem responder às demandas locais, onde grupos resistem e escolhem continuar com um envolvimento com o seu lugar, reafirmando práticas próprias de produção. Em oposição ao paradigma desenvolvimentista que legitima a criminalização desses corpos, há uma série de práticas locais, culturais e artísticas atravessadas pelo léxico da resistência em busca de afirmação e expressão de sua subjetividade.

Propõe-se, então, identificar os fluxos das formas coletivas auto-organizadas que surgem nos territórios alvo do controle como potencialmente capazes de produzir novos espaços urbanos ao tematizarem aquilo que Ihes foi destituído. O que se expressa nos enunciados encontrados em Ceilândia desfaz a aura cosmopolita e modernizadora 
do projeto urbano de Brasília, denunciando, em retrospectiva, como o controle do Estado dos discursos e práticas do urbanismo produziu imagens que não encontram correspondência na atual dinâmica da cidade.

\section{Reação: práticas insurgentes na produção de comum urbano}

Desde 2007, o Programa Jovem de Expressão conduz ações em Ceilândia voltadas para formação e fomento do que denominam empreendedorismo social. A gestão do programa é compartilhada com a Rede Urbana de Ações Socioculturais (RUAS), organização da sociedade civil de interesse público fundada em 2005. O programa tem como propósito "desenvolver ações socioculturais para a promoção, a inclusão e a justiça social para jovens em situação de risco social" (informações apresentadas no Anuário 2017). O protagonismo jovem propõe variadas ações como atividades de acolhimento e promoção de saúde mental, tecnologias sociais baseadas na terapia comunitária integrada, espaço para falas e escutas potencialmente livres de preconceitos. Além disso, um curso pré-vestibular comunitário com professores voluntários muitos deles egressos da UnB - prepara para o acesso ao ensino superior; e um Laboratório de Empreendimentos Criativos investe no fortalecimento de economias solidárias por meio da criação de pequenas empresas. Na expressão dos participantes, o programa Jovem de Expres- 
são é disparador de várias propostas que ambicionam autonomia, acolhimento, envolvimento e integração local para empoderamento da juventude negra e periférica.

Harvey (2014) defende a ideia de comum como meio de inventar solidariedades locais - como na gestão de bairros - ou um comum amplo relacionado às questões ambientais, que impõe o desafio da gestão social para que os benefícios sejam compartilhados por todos. Criar formas de manejo de recursos e de gestão de espaços estaria no horizonte desse arranjo socioespacial. Harvey recorre a Hardt e Negri (2016) quando especula sobre o comum cultural: algo dinâmico que o produto do trabalho e os meios futuros de produção. Um comum que não é apenas a terra compartilhada, pois inclui as nossas línguas e práticas socialmente construídas (HARDT e NEGRI, 2016). Espaços e bens públicos geridos por governos não configuram necessariamente comuns, embora contribuam intensamente para suas qualidades.

Subtraindo a lógica da produção de mais-valia e dos poderes do direito de propriedade, o comum, enquanto questão política, envolve a auto-organização de populações para produzir e se apropriar de bens. Desse modo, o comum não é uma forma específica de ativo ou de processo social, mas uma relação permanentemente maleável entre coletivos autodefinidos e o que produzem por suas práticas de "comunalização". No cerne dessa prática, en- 
contra-se como princípio "a relação entre o grupo social e o aspecto do ambiente tratado como comum será tanto coletiva quanto não mercantilizada - para além dos limites da lógica das trocas e avaliações de mercado" (ibid., p.145).

Tal arranjo de comunalização está presente em práticas coletivas de Ceilândia, que amplificam potências e enunciações dos territórios populares, como a Praça do Cidadão. A praça é um espaço apropriado por coletividades organizadas onde acontecem ações autogestionárias fora de estruturas formais de representação, ou seja, que não estão ligadas ao Estado ou a partidos políticos, sindicatos, entidades de classe e demais organizações hierárquicas, e que, portanto, colocam em evidência a possibilidade de constituição de um bem comum urbano. No local, iniciativas independentes promovem festas, oficinas, debates, desfiles, batalhas de rap entre outras atividades de produção, circulação e divulgação das culturas jovens periféricas.

Tratam-se de ações que reivindicam o direito à cidade, configurando espaços de ativismo a contrapelo de projetos urbanos excludentes - portanto, opostos ao urbanismo como dispositivo de controle. Performam, assim, práticas de insurgência de cidadania que podem ser compreendidas como o que Faranak Miraftab (2016) denomina "planejamento insurgente." O planejamento insur- 
gente - ou conflitivo - compreende práticas contra-hegemônicas e forças de transgressão com poder de liberar a imaginação do planejamento, descolonizando suas condutas e questionando suas prerrogativas. Elaborar novas definições a partir dessa perspectiva envolve reconhecer práticas cidadãs como formas de planejamento.

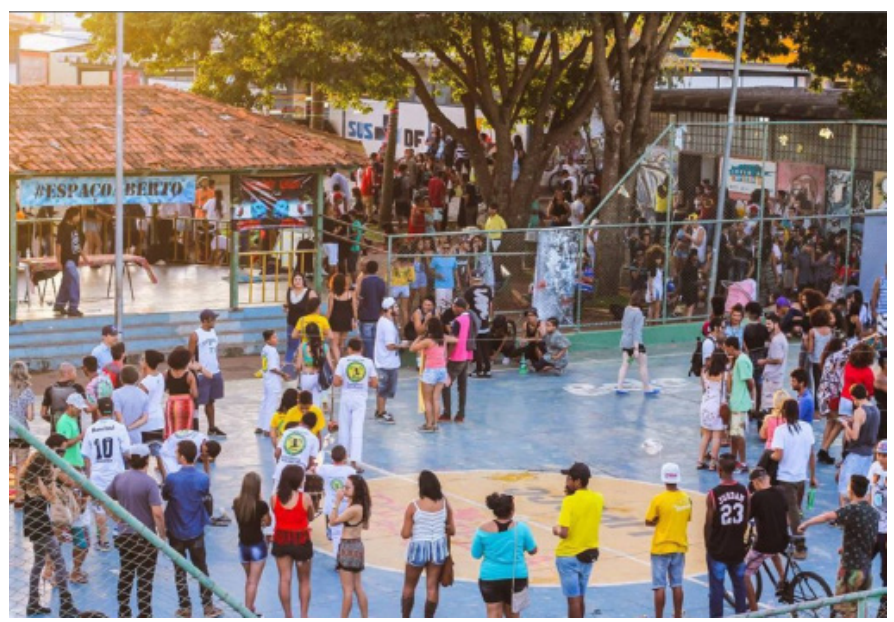

Figura 2 | Praça do Cidadão, 2018

Fonte: Fotografia de Samuel Estrella

Não se pode perder de vista que, em larga medida, tais ações refletem também a ausência de equipamentos públicos, em especial, aqueles destinados à cultura. Ainda assim, mostram energias reunidas e mobilizadas que 
compreendem a cidade como lugar de convergência e compartilhamento, mais do que território a ser controlado e administrado pelo vértice hegemônico. A reação da juventude ativa o espaço público com sentido engajado e propositivo. Ao conduzir suas ações, propõe-se aqui que os grupos tentam romper com as hierarquias e as programações dadas em benefício de um espaço espontâneo e permanentemente reinterpretado, um espaço comum aberto às virtualidades não realizadas. Doron (2007) descreve essa ativação dos espaços públicos como algo ainda pouco explorado pelo campo da arquitetura e do urbanismo - ao menos sistematicamente. Para o autor, a potência crítica da comunalização estaria na possibilidade de pensar um lugar sem programação definida que, justamente por essa razão, estaria em transformação constante.

Ao valorizarem as experiências locais, ao proporem formas compartilhadas de pensar o espaço urbano e, com isso, transformá-lo, os jovens em Ceilândia elaboram um modo alternativo de produzir cidade - já que esse saber, o urbanismo, está sujeito a constantes interferências de sentido e significado. Mais que um espaço público, a Praça do Cidadão pode ser compreendida como um lugar comum, onde não se elabora apenas o presente e as questões da vizinhança; expande-se as fronteiras imaginativas em direção a uma outra cidade: plena em direitos e garantias. 


\section{Cidade Estrutural e segregação socioespacial}

A Cidade Estrutural é uma ocupação originada como assentamento espontâneo de catadores de lixo nos arredores do aterro sanitário de Brasília. A ocupação teve início na década de 1970 e cresceu consideravelmente - de forma desordenada - ao longo dos anos 1990, por ação de trabalhadores da coleta e seleção de resíduos sólidos. Seu nome remete à Via Estrutural, rodovia que atravessa a porção oeste do Eixo Monumental e a conurbação formada por Ceilândia, Taguatinga e Samambaia. A cidade está a $13 \mathrm{~km}$ do Plano Piloto, inserida na Região Administrativa do Setor Complementar de Indústria e Abastecimento (SCIA) ${ }^{4}$. No primeiro cadastro realizado em 1993, foram identificadas 193 famílias vivendo no local. Atualmente "estima-se que a população da Estrutural seja de aproximadamente 40.000 habitantes, sendo apenas 5\% remanescentes de catadores de lixo (informação verbal)" (GUINANCIO, GOMES, 2014; p. 102).

A Estrutural é uma cidade heterogênea cujas características são influenciadas por áreas adjacentes. Os núcleos consolidados, situados próximo à rodovia, apresentam disposição regular da malha urbana que resulta em divisão relativamente proporcional entre habitação e demais

4 Criada em 25/01/2006, é definida pela poligonal compreendida pelo limite do Parque Nacional de Brasília, a DF095 (Estrada Parque Ceilândia), o Córrego do Valo e o Setor Complementar de Indústria e Abastecimento (SCIA). 
atividades. Percorrendo os trechos da cidade, percebe-se o contraste com a Zona Industrial na fronteira a leste, onde lotes e edificações são consideravelmente maiores. Nas bordas do Parque Nacional de Brasília, na porção norte, está o setor Santa Luzia, onde a precariedade é proporcional às ameaças constantes de remoção.

O Movimento Nossa Brasília e o Instituto de Estudos Socioeconômicos (INESC) elaboraram em 2016 a primeira edição do Mapa das Desigualdades. O documento foi inspirado por iniciativas da Rede Nossa São Paulo e da Casa Fluminense, parceiros da Rede Cidades: Por Territórios Justos, Democráticos e Sustentáveis. A pesquisa levantou indicadores de desigualdade em diferentes regiões do Distrito Federal. A Cidade Estrutural apresentou os piores índices. A partir daí uma articulação de grupos locais mobilizou diálogos com os moradores sobre os impactos dos baixos indicadores em seus cotidianos. "Encarando Números na Estrutural" figurou como oportunidade para os moradores reconhecerem e afirmarem suas lutas diárias diante da precariedade resultante de pouca ou nenhuma atuação do Estado. O resultado desse material, em forma de crônicas, evidencia as táticas de sobrevivência por trás dos números reveladores da desigualdade onde

há acima de tudo a energia de pessoas que resistem e insistem em construir suas vidas naquela cidade, por escolha ou por falta de alternativas. Pessoas que chegaram ao Distrito Federal diante das promessas da capital 
da esperança, vindas especialmente do norte e do nordeste, e que encontraram na Estrutural a possibilidade de renda no lixão ou em atividades correlatas (...) O que sim conhecemos é a força e a criatividade daqueles que ali habitam, que fazem da Estrutural não uma mas várias cidades (INESC, 2019).

O chamado 'lixão da Estrutural' foi o maior aterro sanitário de Brasília até 2018, quando foi desativado pelo governo distrital. Ainda que tenha sido uma realização necessária do ponto de vista ambiental, a ação acarretou novos problemas no que diz respeito a aspectos econômicos e sociais. Durante décadas, os moradores da Estrutural enfrentaram ações de despejo e ausência de políticas públicas nas áreas de educação, saúde, segurança, mobilidade, trabalho e renda; e viram ainda mais limitadas suas oportunidades, já que o lixão era sustento para muitas famílias.

Situações como essa demonstram que a crença na igualdade por meio do desenvolvimento capitalista ou a utopia totalizadora e universalista da racionalidade técnica não se efetivou. Como afirma Otília Arantes (1998, p.108), "o desenvolvimento das forças produtivas não significou emancipação humana, ao contrário, as desigualdades não cessam de aumentar". A razão modernizadora permanece influenciando as práticas do urbanismo de caráter ideológico, operando na lógica que comanda a produção de competição e lucro, resultando em segregação socioes- 
pacial de toda ordem, encarnada na Cidade Estrutural. Sem duvidar da agenda social da Arquitetura Moderna em sua gênese, Arantes explica que, por fidelidade aos princípios de racionalização absoluta que definem a lógica social da ordem capitalista, o movimento moderno não estava rompendo com o mundo injusto à sua volta, mas ajudando a dar-lhe forma.

Essa questão é relevante para analisar as intervenções urbanísticas e os programas políticos para a Estrutural nos dias de hoje. Suas diferentes estratégias são muitas vezes programadas de modo abrangente e irrestrito, sem considerar particularidades locais. Não se pretende oferecer uma visão comparativa entre os projetos para Ceilândia ou Cidade Estrutural, mas observar as poucas variações na forma de encarar a problemática. Nos anos 1970, as favelas eram consideradas um problema por sua proximidade aos espaços valorizados do Plano Piloto; eram anos de intenso fluxo de migrantes para um polo de atividades econômicas. A Cidade Estrutural, por sua vez, teve seu crescimento na década de 1990, anos de crise do Estado, quando houve redução do investimento público para o problema da habitação. Isso pode explicar em parte a leniência de governos no trato da questão, que não procuraram dar resposta substantiva para equacionar a questão.

Ceilândia e Cidade Estrutural transpõem o problema so- 
cial para outro patamar pois o déficit de moradia onera os deslocamentos e desequilibra os polos de produção econômica. Assim, mesmo que se quisesse manter a área central de Brasília e seu desenho icônico livre das influências da conurbação, o problema continua reverberando no espaço metropolitano. Há um campo de percepções figurada nas práticas do urbanismo regidas pela simplificação que codifica de forma muito semelhante a maneira de se intervir no espaço, independentemente de particularidades.

Ceilândia é resultado de um projeto urbano assentado em princípios do ideário urbanístico funcionalista moderno. A Estrutural é um território fragmentado e originalmente construído em torno da atividade econômica no lixão. Ceilândia resulta de dispositivos de agenciamento e acomodação; a Estrutural reflete vagueza e descompromisso no trato com a questão urbana. No lugar de alternativas interessadas em conciliar esse quadro multifacetado, desenha-se perspectivas de intervenção preocupadas sobretudo com remoções. Novamente, as remoções podem ser consideradas como solução urbanística concentrada em solucionar a infraestrutura ou a ocupação de determinada região da cidade, sem enfrentar radicalmente as condições que levaram centenas de famílias a estabelecer ali seus locais de moradia. 


\section{Emergência de movimentos culturais na pro- dução do espaço}

O projeto "Inventário Cultural Participativo sobre Cultura e Memória na Estrutural-DF", realizado entre 2016 e 2018 pelo Ponto de Memória da Estrutural, identificou, registrou e mapeou iniciativas artístico-culturais da cidade, expressas em diversas linguagens. Esse trabalho resultou em um catálogo de agentes culturais. A desigualdade socioeconômica é proporcional à quantidade de indivíduos e coletivos: são muitos, variados e potentes artistas e produtores de cultura. O MECE - Movimento de Educação e Cultura da Estrutural, atualmente funcionando na Casa dos Movimentos da Estrutural, reúne coletivos e movimentos sociais para o desenvolvimento de metodologias participativas para o inventário. São práticas que incluem rodas de memórias e oficinas de capacitação sobre patrimônio com patrocínio do Fundo de Apoio a Cultura do DF. Em 2011, por meio do Programa Pontos de Memória do Instituto Brasileiro de Museu IBRAM/MinC, foi inaugurado o Ponto de Memória da Estrutural, resultando em exposições, projetos de extensão da universidade e no planejamento da implantação do Museu Comunitário da Estrutural.

A Cidade Estrutural se revela como lugar onde ativistas lutam pela memória e construção identitária, com forte sentido de valorização da história de resistência da popu- 
lação. Taticamente, estimulam o uso e a apropriação de espaços de educação não formais. São inúmeros exemplos de espaços autogeridos, como a Cooperativa Sonho de Liberdade, organização que trabalha com reciclagem de madeira descartada produzindo móveis e objetos, um projeto idealizado por ex-detentos do sistema penitenciário. Foram citados no inventário ainda o Centro Cultural de Economia Solidária; o Movimento de Mulheres; a Casa da Paternidade; a Biblioteca Comunitária Catando Palavras. Ressalta-se aqui o caso da Editora Popular Abadia Catadora.

A Editora foi criada em 2011, estimulada por debates do Ponto de Memória, a fim de incentivar a leitura e a escrita, para que a própria população pudesse produzir livros e contar sua história. Abadia é Maria Abadia Teixeira de Jesus, ex-catadora de materiais recicláveis, ativista e liderança comunitária. Inspirada na editora popular argentina Eloísa Cartonera, teve apoio das embaixadas da Argentina e Espanha e do Curso de Museologia da Universidade de Brasília. A editora é

estruturada nos moldes de uma cooperativa, funcionando de forma participativa [...] é um canal para textos que estimulem a reflexão e a discussão política, além de apoiar o processo de construção da memória social e coletiva por meio do lançamento de escritores locais (Inventário Cultural da Estrutural, 2019). 
Aspecto comum a todas essas ações, está a proposta de tecer uma narrativa própria, de contar a própria história. A força de contar a própria história aparece nos escritos autobiográficos de Maya Angelou, Chimamanda Adichie e Grada Kilomba. A educadora bell hooks salienta o compromisso de práticas pedagógicas engajadas na criação de novas linguagens; a importância da descentralização da autoridade na escrita discursiva e política que sinaliza uma virada epistêmica na produção de conhecimento. São novas racionalidades que indicam o fortalecimento dos movimentos de base antirracistas, feministas, LGBTQl, exigindo outras posturas, outros diálogos e novas formas de acesso aos espaços de poder e decisão como a universidade e a política representativa. Os projetos culturais existentes na periferia das grandes cidades produzem espaço e implicam desativações e reinvenções.

Retomemos o comum como princípio político. Como proposto por Dardot e Laval (2017), o comum desativa as conexões Estado-público e o binarismo público-privado, afirmando que há experiências de caráter público que não são estatais, mas elaboradas e ativadas em contraponto à propriedade privada, ao neoliberalismo e seus fenômenos relacionados ao modo de urbanização. Não se tratam de bens comuns, mas de uma força social que anima modelos alternativos e formas de organização. A emergência estratégica do comum conduz a formas originais de ação e discurso, esclarecendo "princípios que podem orien- 
tar as lutas, unir as práticas dispersas à forma que uma nova instituição geral das sociedades poderia assumir" (DARDOT e LAVAL, 2017., p.16). Os coletivos ativistas e organizações sociais presentes e atuantes na Estrutural precisam do Estado na medida em que podem utilizar fundos e programas na área da cultura determinantes para o surgimento das ações. Entretanto, a elaboração, gestão e condução das atividades se dá diretamente em comunidade, o que amplia e liberta os nexos da palavra participação - expressão tão repetida, cooptada e esvaziada de sentido. Participação não é uma etapa de ação, mas a própria premissa da sua existência. Como propõem Dardot e Laval (2017, p. 15),

na realidade, se hoje a questão do comum é tão importante, isso se dá porque ele anula brutalmente as crenças e esperanças progressistas depositadas no Estado. Está claro que se trata não de fazer eco à condenação neoliberal das intervenções sociais, culturais ou educacionais do Estado, mas de resgatá-las de seus limites burocráticos e submetê-las à atividade social e à participação política da maioria.

Quijano (2005) afirma que qualquer democratização possível da sociedade na América Latina deve ocorrer com redistribuição radical do poder. Poder político, econômico e também simbólico, já que a profunda expropriação das populações colonizadas exige que se reintroduza práticas de povos alijados da produção de conhecimento. Seus sistemas de produção de sentido, seus universos sim- 
bólicos, seus padrões de expressão e de subjetividade foram expropriados em um longo processo que culminou na "colonização das perspectivas cognitivas, dos modos de produzir ou outorgar sentido aos resultados da experiência material, do imaginário, do universo das relações, em suma, da cultura" (ibid., p.121). Com a elaboração eurocêntrica de modernidade (forjada na codificação civilizado-primitivo; mítico-científico; irracional-racional; tradicional-moderno) pautou-se uma perspectiva binária e dualista de conhecimento, impondo-se mundialmente como hegemônica no mesmo fluxo de expansão do domínio colonial da Europa sobre o mundo. Dessa forma, Quijano afirma que "é tempo de aprendermos a nos libertar do espelho eurocêntrico onde nossa imagem é sempre, necessariamente, distorcida. É tempo, enfim, de deixar de ser o que não somos" (QUIJANO, 2005., p.123).

$\mathrm{Na}$ esteira das reflexões de Quijano, identificam-se as ações na Estrutural como forças insurgentes. São ações que não prescindem do Estado, mas o colocam em posição relativa. Os coletivos urbanos da Estrutural pautam suas ações a partir do conjunto das contradições expressas em um espaço, mas também criam uma nova relação com a materialidade construída amparada por trocas que, no limite, fortalecem o imaginário político. Em nossa interpretação, essas formas insurgentes de ações desenham um campo de forças e articulam a heterogeneidade desses territórios (sobretudo de gênero e raça) contra as 
unidades referenciais e normativas do planejamento urbano e do urbanismo. Ao reivindicarem novas possibilidades de leitura dos espaços urbanos, apontam para alternativas abertas e plurais de produção urbana, pois esta não é resultado apenas da constituição material (os projetos, as normas) mas apresenta dimensões simbólicas, referenciais e imaginárias em que as coisas não estão dadas, mas, como propõe Glissant (2010), estão em permanente relação, quer dizer, sendo mutuamente influenciadas por todos os sujeitos.

Nesse processo, há obstáculos. Como observado por Federici (2010), formuladores de políticas públicas redescobriram recentemente que a gestão coletiva de recursos pode ser mais produtiva e eficiente do que a privatização e a estatização em alguns casos, passando a ser vista como importante para o próprio funcionamento dos mercados. Ainda assim, as estratégias de controle incorporadas na prática do urbanismo nunca atingem hegemonias completas. Inevitavelmente, aqueles que ficam à margem das partilhas vêm produzindo extraordinárias insurgências (urbanas), e a cidade se tornou campo ampliado experiencial da vida política.

Talvez os atores aqui considerados apostem nessa mediação (reação) por serem constantemente confrontados por práticas urbanísticas homogeneizadoras. A partir daí, procuram entender a cidade - presente e futura - como 
território comum, em que a participação e o diálogo favorecem o reconhecimento mútuo. Em suma: apontam para um novo horizonte da experiência urbana.

\section{Considerações}

Em uma aproximação inicial às práticas coletivas em territórios populares, a ideia de comum surge como figura potente de compreensão desses lugares. O conceito de comum pode ser visto como uma chave de interpretação das práticas contemporâneas de produção, ocupação e apropriação de espaço produzidas por aqueles que muitas vezes estão alijados dos processos decisórios de projeto e intervenção na cidade. Embora seja objeto de investigação de várias correntes de pensamento, o comum tem sido apresentado como uma formulação que se opõe à lógica neoliberal de acumulação da competitividade e individualidade figurada em diversas práticas urbanísticas - como nas situações aqui descritas. Assim, identificar práticas de produção de comum na periferia do Distrito Federal surge como possibilidade de enfrentar os complexos problemas de nossos tempos e inventar novas formas de colaboração e produção no campo da Arquitetura e do Urbanismo.

As referências trazidas mostram que os interesses de 
pesquisa nesse campo se ampliaram recentemente. Também é notável a quantidade de trabalhos junto às ocupações urbanas, movimentos sociais, ativistas e artífices, demonstrando que territórios populares vêm sendo cada vez mais reconhecidos por suas características de cooperação e solidariedade. Longe de se impor como resposta livre de conflitos e contradições, as resistências urbanas tensionam as teorias urbanas. Sem dúvida, há limites na abordagem a respeito do comum como energia política emancipadora. No campo hegemônico do urbanismo, no qual hábitos e formas de pensamento se pautam mais pela convergência do que pelas experiências de comunalização, as políticas do comum são relativamente tangentes e perdem espaço para as dimensões operativas mais imediatas. Ainda assim, pela ausência de relatos totalizadores, as práticas aqui descritas levam a valorizar os lampejos de dissenso em uma trajetória urbana marcada pela desigualdade, exclusão, domínio e controle. No presente, formas de resistência transformam territórios da cultura popular: observar, reconhecer e abrir espaços para que seus próprios atores se façam ouvir pode ser um caminho. 


\section{Referências}

AGAMBEN, Giorgio. $\mathbf{O}$ amigo \& $\mathbf{O}$ que é um dispositivo. Chapecó: Argos, 2014.

ALTBERG, Ana; MENEGUETTI, Mariana; KOSLOWSKI, Gabriel (Coord.). 8 reações para o depois. Rio de Janeiro: Rio Books, 2019.

ARANTES, Otília B. Fiori. Urbanismo em fim de linha e outros estudos sobre o colapso da modernização arquitetônica. São Paulo: Editora Universidade de São Paulo, 1998.

BARREIRA, Marcos; BOTELHO, Maurilio. O Exército nas ruas: da Operação Rio à ocupação do Complexo do Alemão. Notas para uma reconstituição da exceção urbana. In BRITO, F. et. al. (orgs.) Até o último Homem: visões cariocas da administração armada da vida social. São Paulo: Boitempo, 2013, pp. 115-128.

BATISTA, Vera Malaguti. O Alemão é muito mais complexo. 2011. Disponível em:<www.anf.org.br/o-alemao-e-muito-mais-complexo>. Acesso em: 20/02/2020.

BRITO, F. Considerações sobre a regulação armada de territórios cariocas. In BRITO, F. et. al. Até o último homem: visões cariocas da administração armada da vida social. São Paulo: Boitempo, 2013. p. 79-114. 
COSTA, Lucio. Brasília. in XAVIER, Alberto (org.). Lucio Costa: sobre arquitetura. Porto Alegre: UniRitter, 2007, p. 275-276.

DARDOT, Pierre. Comum: ensaio sobre a revolução no século XXI. Pierre Dardot, Christian Laval; tradução Mariana Echalar. São Paulo: Boitempo, 2017.

DELEUZE, Gilles. O mistério de Ariana. Ed. Vega - Passagens. Lisboa, 1996.

DERNTL, Maria Fernanda. Além do plano: a concepção das cidades-satélites de Brasília. Arquitextos 221, Ano 19, outubro de 2018. Disponível em: <https://www.vitruvius.com.br/revistas/read/arquitextos/19.221/7150>. Acesso em: 23/11/2019.

DORON, Gil M. Transgressive Urban Space. In FRANCK, Karen; STEVENS, Quentin. Loose Space: Possibility and Diversity in Urban Life. Londres: Routledge, 2007, p. 210228.

ESCOBAR, Arturo. Encountering development: The making and unmaking of the Third World. Princeton: Princeton University Press, 1995.

FEDERICl, Silvia. O feminismo e as políticas do comum. São Paulo: Elefante, 2017. 
FOUCAULT, Michel. Sobre a História da sexualidade. In: Microfísica do poder. Rio de Janeiro: Graal, 2000. p. $243-27$.

GLISSANT. Édouard. Poética da Relação. Lisboa: Sextante, 2011.

GUINANCIO, Cristiane; GOMES, Viridiana Gabriel. Brasília e assentamentos urbanos informais: a Vila Estrutural. In: SABOIA, Luciana; DERNTL, Maria Fernanda (org.) Brasília 50+50: cidade, história e projeto. Brasília: Editora UnB, 2014.

GOUVÊA, Luiz Alberto de Campos. Brasília: a capital da segregação e do controle social. Uma avaliação da ação governamental na área de habitação. São Paulo: Annablume, 1995.

HARDT, Michael; NEGRI, Antonio. Bem-estar comum. Rio de Janeiro : Record, 2016.

HARVEY, David. Cidades rebeldes: do direito à cidade a revolução urbana. São Paulo: Martins Fontes, 2014.

INESC - Instituto de Estudos Socioeconômicos. Uma cidade em crônicas: encarando números na Estrutural. Brasília, 2019.

MENEGAT, Marildo. A crítica do valor bate à sua porta. In 
BRITO, F. et. al. Até o último homem: visões cariocas da administração armada da vida social. São Paulo: Boitempo, 2013.

MIRAFTAB, Faranak. Insurgência, planejamento e a perspectiva de um urbanismo humano. Revista Brasileira de Estudos Urbanos e Regionais, Recife, v.18, n.3, p. 363377, 2016.

OLIVEIRA, João Pacheco de. Pacificação e tutela militar na gestão de populações e territórios. Revista Mana vol.20, Rio de Janeiro 2014.

PAVIANI, Aldo. A construção injusta do espaço urbano. In: PAVIANI, Aldo (Org.). A conquista da cidade: movimentos populares em Brasília. Brasília: Editora da UnB, 1991. p. 115-142.

PEIXOTO, Elane Ribeiro et al. O rap de Ceilândia. In: ENCONTRO NACIONAL DA ANPUR. 2017, São Paulo. Anais eletrônicos. São Paulo: ANPUR, 2017.

PONTO DE MEMÓRIA DA ESTRUTURAL. Inventário Cultural da Estrutural. Brasília, 2018. CD-ROM.

ROLNIK, Raquel. Paisagens para renda, paisagens para vida. Revista Indisciplinar, Belo Horizonte, v. 5, n. 1, p.18-43, jul. 2019. 
SPIVAK, Gayatri Chakravorty. Pode o subalterno falar? Belo Horizonte: Editora da UFMG, 2010.

TEIXEIRA, Eduardo Tomazine. La pacification des favelas de Rio de Janeiro: une "contre-insurrection préventive?". In: Nicolas Pinet (Org.). Projets politiques et Luttes sociales: expériences latino-américaines. Paris: I'Harmattan, 2012, p. 53-65.

QUIJANO, Anibal. Colonialidade do poder, Eurocentrismo e América Latina. In: A colonialidade do saber: eurocentrismo e ciências sociais. Perspectivas latino-americanas. Buenos Aires: CLACSO, Consejo Latinoamericano de Ciencias Sociales, 2005. 